\title{
Uma Análise da Homofobia Sob a Perspectiva da Análise do Comportamento
}

\author{
Leandro Herkert Fazzano ${ }^{1}$ \\ Programa de Pós-Graduação em Análise do Comportamento da Universidade Estadual \\ de Londrina, Londrina, PR, Brasil \\ Alex Eduardo Gallo \\ Departamento de Psicologia Geral e Análise do Comportamento da Universidade Estadual \\ de Londrina, Londrina, PR, Brasil
}

\section{Resumo}

O termo homofobia refere-se a uma expressão coloquial que exprime atitudes e comportamentos negativos, de medo ou de ódio, contra gays e lésbicas, sendo que mais de um terço dos homossexuais são vitimas de violência, embora as causas são pouco estudadas. Definindo o fenômeno em termos da análise do comportamento, como sendo um conjunto de comportamentos complexos, envolvendo comportamentos operantes e respostas emocionais, relativos às varias modalidades de agressão (seja física, psicológica ou sexual) contra indivíduos homossexuais ou que se identifiquem com a cultura homossexual, relacionando-se com o conceito de controle aversivo. Ao agressor, a presença de homossexuais poderia ser considerada aversiva, havendo, portanto, uma maior probabilidade de que o sujeito se comporte de forma agressiva. Essa aversividade pode ter sido aprendida ao longo da história de vida do agressor. Do ponto de vista da vitima, a agressão pode ser considerada como punição aos seus comportamentos. Pode-se observar a presença de efeitos colaterais, como respostas emocionais, e o reforçamento de comportamentos contrários aos punidos. Ainda se fazem necessários mais estudos, principalmente sobre a prevalência da agressão junto à população homossexual. Entender as causas de tal fenômeno, sua incidência na população, e as formas como se manifesta faz-se importante para compreender e combater agressões. Além disso, a partir do conhecimento do fenômeno, é possível pensar em diversas estratégias que poderiam aumentar o número de denúncias, se aproximando do número real de casos existentes, o que daria maior visibilidade ao problema, refletindo em políticas públicas de combate a essa violência.

Palavras-chave: Homofobia, análise do comportamento, controle aversivo, agressão contra homossexuais.

\section{An Analysis of Homophobia under Behavior Analysis Perspective}

\begin{abstract}
The term homophobia refers to a colloquial expression that expresses negative attitudes and behaviors, fear or hatred against gays and lesbians, and more than one third of homosexuals are victims of violence, although its cause is not studied. Defining the phenomenon in terms of behavior analysis, as complex behaviors involving operant behaviors and emotional responses, related to various forms of aggression (whether physical, psychological or sexual) against homosexuals or individuals who identified with the homosexual culture, linking up with the concept of aversive control. To the aggressor, the presence
\end{abstract}

Endereço para correspondência: Av. Higienópolis, 1338, Apto. 33, Londrina, PR, Brasil 86015-010. Fone: (43) 9985-2469, (018) 815-0202. E-mail: leandrofazzano@hotmail.com 
of homosexuals could be considered aversive, and therefore there is a greater probability that he/she behaves aggressively. This aversiveness may have been learned along the life history of the offender. From the point of view of the victim, aggression can be seen as punishment for their behavior. Is possible to observe the presence of side effects, such as emotional responses, and reinforcement of behavior opposed to punished. Yet, more studies are necessary, mainly on the prevalence of aggression on the homosexual population. Understand the causes of this phenomenon, its incidence in the population, and the ways it manifests is important to understand and combat aggressions. Moreover, from knowing the phenomenon, it is possible to think in different strategies that could increase the number of denouncement, approaching the actual number of existing cases, which would give greater visibility to the problem, reflected on public policies to combat such violence.

Keywords: Homophobia, behavior analysis, aversive control, aggression against homosexuals.

\section{Un Analisis de la Homofobia Bajo la Perspectiva del Analisis del Comportamiento}

\section{Resumen}

El término homofobia se refiere a una expresión coloquial que expresa actitudes y comportamientos negativos, de miedo u odio contra gays y lesbianas, y más de un tercio de los homosexuales son víctimas de la violencia, aunque las causas no se comprendan bien. Definición del fenómeno en términos de análisis de comportamiento, como un conjunto de comportamientos complejos que involucran conductas operantes y respuestas emocionales, en relación con formas de agresión (sea física, psicológica o sexual) contra homosexuales o personas que se identifican con la cultura homosexual, en relación con el concepto de control aversivo. El autor, la presencia de homosexuales podría considerase aversivo, com una mayor probabilidad de que el sujeto se comporte agresivamente. Esta aversión puede haber aprendido en la vida del delincuente. Desde el punto de vista de la víctima, el ataque puede ser visto como un castigo por su comportamiento. Se puede observar la presencia de efectos secundarios, tales como respuestas emocionales, y refuerzo del comportamiento contrario a castigados. Aunque se necesitan más estudios, sobre todo la prevalencia de la agresión por parte de la población homosexual. Comprender las causas de este fenómeno, su incidencia en la población, y las formas em que se manifiestan resulta importante para comprender y combatir las agresiones. Además, desde el conocimiento del fenómeno, es posible pensar en diferentes estrategias que podrían aumentar el número de denuncias, acercándose al número real de casos, lo que daría mayor visibilidad al problema, lo que refleja las políticas públicas para combatir la violencia.

Palabras clave: Homofobia, análisis del comportamiento, control aversivo, agresión contra homossexuales.

"Irmãos são agredidos ao andarem abraçados em Camaçari; um morreu" (G1 Bahia, 2012). Essa manchete foi postada no portal de notícias do G1, no dia 27 de junho de 2012. Segundo relato, os irmãos gêmeos teriam sido atacados ao serem confundidos com um casal homossexual, sendo que os agressores não apresentaram justificativas para o seu ato. Ao observar a quantidade de notícias relacionadas a esse tema é possível perceber uma crescente visibilidade da agressão contra homossexuais, denominada popularmente de homofobia. Todavia, apenas tornar o fenômeno visível não é explicá-lo e se faz necessário compreender o que se está chamando por homofobia.

O termo homofobia refere-se a uma expressão coloquial, de uso popular, utilizada para exprimir atitudes e comportamentos negativos, de medo ou de ódio, contra gays e lésbicas (Nardi \& Bolton, 1991; O’Brien, 2001). Embora o termo 
seja popularmente empregado, alguns autores (Adams, Wright, \& Lohr, 1996; O’Brien, 2001; Parrott, 2008; Parrott \& Zeichner, 2005), sugerem que os termos "preconceito antigay" (antigay prejudice) ou "preconceito sexual" (sexual prejudice) seriam melhor utilizados, uma vez que o termo "homofobia" poderia conotar uma resposta fóbica psicopatológica, não refletindo a extensão de agressões e atitudes contra homossexuais. Mais além, tais explicações apresentam-se pouco funcionais para a compreensão do fenômeno, suas consequências e causas.

Pesquisas indicam que mais de um terço dos homens e mulheres homossexuais são vítimas de violência e $94 \%$ relataram algum tipo de vitimização devido a sua sexualidade (Parrott $\&$ Zeichner, 2005), sendo a maioria das vítimas homens homossexuais ou com características mais femininas (Bernardes et al., 2012; O'Brien, 2001). Mais além, encontra-se na literatura que há relação entre orientação sexual e restrições ao mercado de trabalho, sendo que os homens gays enfrentam perspectivas mais pobres no mercado de contratação do que seus colegas heterossexuais (Drydakis, 2009). No Brasil, foi realizado, no ano de 2011, pela Secretária de Direitos Humanos uma caracterização da violência homofóbica no país, através de denúncias realizadas ao disque 100 , contabilizando o total de 6.809 relatos de violações dos direitos humanos contra lésbicas, gays, bissexuais e transexuais (LGBT), envolvendo 1.713 vítimas e 2.275 suspeitos (Bernardes et al., 2012). Segundo os dados levantados, corroborando com O’Brien (2001), a maior população vítima pertence ao gênero masculino, na faixa etária entre 15 a 29 anos. Um dado interessante apontado no relatório mostra que a maioria das violações aos direitos humanos da vítima ocorrem em vias públicas e dentro de casa, sendo que $61,9 \%$ das vítimas conhece o seu agressor. As formas de violência reportadas mais frequentes foram: violências psicológicas $(42,5 \%)$, discriminação $(22,3 \%)$ e violências físicas $(15,9 \%)$. É valido ressaltar que tais números são referentes apenas às denúncias realizadas ao disque 100 , podendo não expressar significativamente a realidade brasileira.
Sobre as causas, não há muitos estudos que apontem para as possíveis explicações de tal comportamento. O que se encontra na literatura são causas "mentalistas", sobretudo de teorias psicodinâmicas, que explicariam a homofobia como uma ameaça aos impulsos homossexuais do próprio indivíduo agressor, causando negação, repressão, ou reação de formação, um tipo de homossexualidade latente (Adams et al., 1996), ou como sendo uma defesa egóica (Herek, 1995, citado por O'Brien, 2001). Tais formas de explicações são de pouca (ou nenhuma) ajuda para compreender o fenômeno da homofobia, primeiramente porque atribuem as causas da violência a uma entidade ontológica, a qual é inacessível e imutável. Desconsideram-se os contextos nos quais este indivíduo esteve inserido ao longo de sua vida, e, não raro, acaba-se por desconsiderar, também, o sujeito que aprende formas de agir no mundo, ensinado através de seus pares.

Mais além, ao afirmar que a homofobia é uma defesa contra os próprios impulsos sexuais, dito como uma "formação reativa", seria o mesmo que tomar "a parte pelo todo". Ou seja, ao considera-se tal explicação, estar-se-ia assumindo que todas as pessoas homofóbicas seriam homossexuais, os popularmente chamados de "enrustidos". É possível que para alguns indivíduos isto seja verdade, mas a generalidade de tal conceituação é perigosa, pois desconsidera as idiossincrasias.

Ademais, ao atribuir as causas a uma função egóica, imputaria a responsabilidade dos atos violentos a uma entidade metafisica, ausentando algumas agências sociais, como a educação ou o próprio governo, de tornarem-se ativos em prol de mudanças sociais. Pois bem, "se é algo do próprio indivíduo, por que eu, Estado, deveria intervir?". Nada mais se faz do que buscar "bodes expiatórios".

Uma possível melhora na compreensão pode ser dada ao definir o fenômeno em termos analítico-comportamentais. $\mathrm{O}$ behaviorismo radical, enquanto filosofia de uma ciência comportamental, trabalha com o comportar-se, com a interação entre o organismo e o ambiente. Segundo Matos (1999, p. 45), "o behaviorista radical não trabalha propriamente com o comporta- 
mento, ele estuda e trabalha com contingências de reforçamento, isto é, com o comportar-se dentro de contextos". Mas, para analisar o contexto, faz-se necessário, inicialmente, definir o comportamento que será estudado.

Dessa forma, uma possível definição de homofobia em termos comportamentais seria a de um conjunto de comportamentos complexos, envolvendo comportamentos operantes e respostas emocionais, relativos às várias modalidades de agressão (seja física, psicológica ou sexual) contra indivíduos homossexuais ou que se identifiquem com a cultura homossexual.

Pode ser considerado como um comportamento operante, pois pode ser aprendido ao longo das relações do indivíduo em diferentes contextos ao longo da sua vida, como por exemplo, a interação com alguma instituição religiosa mais ortodoxa. Outro fato importante que auxilia compreender a homofobia como comportamento operante dá-se mediante a seleção e manutenção pelas consequências. As consequências do comportar-se retroagem sobre o organismo, selecionando-o, ou seja, alterando a probabilidade do mesmo ocorrer novamente em uma situação parecida (Baum, 2005/2008; Skinner, 1953/2003). Chamam-se de reforçadoras as consequências que aumentam a probabilidade de emissão do comportamento, enquanto que a diminuição da probabilidade por uma consequência dá-se o nome de punição (Skinner ${ }^{2}, 1953 / 2003$ ).

Ao definir a homofobia em termos de comportamento operante, não estamos afirmando que há um comportamento operante, mas sim, uma classe de respostas com as mais diversas topografias, como bater, insultar, torturar, espancar, excluir, discriminar, entre outras. De acordo com Baum (2005/2008, p. 100), "uma classe ou categoria funcional é definida pelo que seus membros fazem - como agem ou funcionam - e

\footnotetext{
A punição não é o único processo pelo qual classes de respostas diminuem sua probabilidade. O próprio reforçamento de uma classe de respostas já ocasiona a diminuição de outras classes que não a selecionada. Também há o processo de extinção comportamental, pelo qual, um comportamento não mais produz a consequência reforçadora que o mantinha.
}

não por sua composição ou aparência e segundo Matos (1999, p. 51), "para o behaviorista radical, são definidos como classe exatamente pela natureza da mudança que produzem". Denomina-se, então, de classe de resposta não pela forma (topografia) que o comportamento assume, mas sim, sua função.

Ao se falar em função, está se falando das possíveis causas do comportamento, as variáveis ambientais envolvidas em seu controle e manutenção. Segundo Skinner (1953/2003) "uma 'causa' vem a ser uma 'mudança em uma variável independente' e um 'efeito', uma 'mudança em uma variável dependente'. A antiga 'relação de causa e efeito' transforma-se em uma 'relação funcional'" (p. 24). Para reconhecer a função de um comportamento, é necessário recorrer à análise funcional, a qual consiste em descobrir as variáveis que influenciam e controlam o comportamento, seja a história de vida do organismo, o contexto e as consequências. Vale ressaltar que, para a realização de uma análise funcional, faz-se necessário a experimentação (manipulação de variáveis) e, devido a aspectos éticos, o presente artigo versará sobre o estabelecimento de uma hipótese funcional que possa auxiliar na explicação da homofobia.

Dessa forma, uma possível maneira de compreendermos a homofobia, esta forma de violência que incide sobre um elemento tão idiossincrático como a sexualidade, possa ser melhor compreendido através do conceito de controle aversivo.

\section{Controle Aversivo e Homofobia ${ }^{3}$}

Ao se falar em controle aversivo, tem-se a ideia de:

eventos que, no linguajar comum, chamamos de "irritantes", "desconfortáveis", "dolorosos", "desagradáveis", "nocivos" e

3 Optou-se aqui por fazer um recorte didático de uma contingência de três termos (antecedente, resposta, consequente). Embora as contingências envolvidas nas agressões possam envolver mais termos, a análise apresentada aqui poderá servir como uma base para a compreensão do fenômeno. 
assim por diante. A maioria desses termos envolve um domínio de referências não comportamental que, provavelmente, não será adequado para uma análise funcional. Com um sinônimo . . . o termo "aversivo" é mais neutro que qualquer um desses adjetivos e tem a vantagem de sugerir a noção apropriada de "evitar", "mover-se para longe de" ou "fugir de" uma situação" (Millenson, 1967/1975, p. 384).

Imaginemos uma pessoa dita homofóbica, que se depara, como na notícia trazida pelo portal G1, com dois homens abraçados e os agride. O que se pode dizer sobre tal episódio? Inicialmente, não muito além do fato de que os dois homens foram agredidos devido a demonstração pública de afeto por alguém do mesmo sexo. Excluindo-se outras variáveis como uma possível embriaguez do agressor, o que se tem é uma análise contextual da agressão, ou seja, na presença de uma ou mais pessoas reconhecidas como homossexuais, observa-se um aumento da probabilidade da emissão de comportamentos agressivos por parte do sujeito homofóbico.

Todavia, a presença de homossexuais, como estímulo discriminativo, pouco nos explica sobre as "causas" da agressão. Uma possível melhora no entendimento da situação se dê através do conceito de reforçamento negativo. De acordo com Millenson (1967/1975), "os reforçadores negativos constituem-se daqueles eventos cujo término (ou redução na intensidade) fortalecerá e manterá operantes" (p. 383). Voltando-se ao exemplo, poderíamos assinalar a agressão como uma forma de remover, reduzir o estímulo. Ou seja, ao agressor, a presença de homossexuais seria considerada aversiva, havendo, portanto, uma maior probabilidade de que o sujeito se comporte de forma agressiva. Ressalta-se que apenas a redução na intensidade do estímulo aversivo já é suficiente para que ocorra o reforçamento das respostas. Caso considerássemos apenas o término como reforçador, infelizmente, todo o caso de violência seria acompanhado de morte, posto que o estímulo seja outro ser humano.

Outro ponto a ser relembrado é que "agressão" não se configura apenas na modalidade de ataques físicos contra a vítima. Obviamente, esta forma caracteriza-se pela sua gravidade, pois causa dano a integridade física da vítima, impondo-se desde uma leve dor a um atentado contra a vida (Cassado, Gallo, \& Willians, 2003; Day et al., 2003). Já a violência psicológica caracteriza-se por danos à individualidade, à autoestima, à moral ou à socialização, através de atos que menosprezem, degradem, humilhem, aterrorizem, negligenciem, rejeitem, ridicularizem, ignorem ou isolem outro individuo (Day et al., 2003; Kairys, Johnson, \& Committee on Child Abuse and Neglect, 2002). Também se pode falar em violência sexual, a qual se configura como a exposição de outrem a conteúdos ou atos sexuais, valendo-se de força física ou mesmo de pressões psicológicas para tal (Day et al., 2003). Há na literatura outros tipos de violência, demonstrando assim que a agressão física não é a única existente.

É valido fazer uma ressalva. O comportamento é definido como "violência" ou "agressão" dada sua função em determinados contextos. Por exemplo, dois amigos que se referem um ao outro como "viadinho" - termo geralmente usado com caráter pejorativo - poderiam não estar se agredindo; tal comportamento poderia ter função de obter a atenção do outro, ou de expressar entrosamento e intimidade entre eles, dado seu contexto de interação. Todavia, se o termo for usado e gerar na vítima o efeito de se sentir triste, constrangida, humilhada ou de ter sido agredida, poderia, então, se caracterizar como uma situação em que houve agressão verbal, um episódio de violência psicológica.

Torna-se, então, questionável o motivo de se considerar a presença de homossexuais como sendo estímulo aversivo. Deveras, não há, nesse caso, algo em si, no próprio estímulo, que seja aversivo e este parece ser um caso de aprendizagem. A Análise do Comportamento compreende a aprendizagem como "todo e qualquer processo de interação entre um organismo vivo e seu ambiente, que produza alteração no repertório comportamental desse organismo, podendo envolver a aquisição e a extinção de um comportamento" (Haydu, 2009, p. 15). Quanto à aquisição ou ex- 
tinção de comportamentos, notam-se três processos distintos: a modelagem do comportamento, que ocorre em termos de reforço diferencial, o seguimento de instruções (regras) e a imitação de um modelo de comportamento ou modelação.

Em um caso de homofobia, muito possivelmente poderá se encontrar os três processos acima mencionados, relacionados ao desenvolvimento desse tipo de preconceito. Para exemplificar, pode-se imaginar que uma pessoa seja homofóbica devido a um modelo parental ou de seus pares, ou ainda, que tenha, ao longo de sua vida, frequentado instituições ortodoxas que pregam contra a homossexualidade. Mais provável é que todos os três processos de aquisição de comportamento estejam envolvidos no desenvolvimento do preconceito e de agressões contra homossexuais.

Falando-se da manutenção das agressões por homofobia, estaríamos nos referindo às consequências do comportamento do agressor, pois "as consequências do comportamento podem retroagir sobre o organismo ... podem alterar a probabilidade de o comportamento ocorrer novamente" (Skinner, 1953/2003, p. 65). Ou seja, estamos falando sobre os eventos que ocorrem contingentes à agressão.

Já mencionamos anteriormente que a presença de homossexuais pode ser considerada, pelo homofóbico, como um estímulo aversivo, tendo o comportamento a função de remoção dessa estimulação. Concomitante ao reforçamento negativo, pode-se também falar do reforçamento positivo, caracterizado pela apresentação de uma consequência contingente ao comportamento e que aumenta a probabilidade do mesmo em situações semelhantes. Talvez uma melhor maneira de diferenciá-los se de, de acordo com Sidman (1989/2003):

Quando produzimos coisas ou eventos que usualmente consideramos uteis, informativos, ou agradáveis em si mesmos, estamos sob controle de contingencias positivas. Mas quando nos livramos, diminuímos, fugimos ou nos esquivamos de eventos perturbadores, perigosos ou ameaçadores, reforçadores negativos estão no controle; com esse tipo de controle eu falo de coerção. (p. 56)
Em uma situação em que houve uma agressão, como no exemplo já citado, além do possível reforçamento negativo, ainda pode-se hipotetizar sobre a existência de reforço social, fornecido pelos pares, através da aprovação do grupo. De acordo com Skinner (1953/2003)

Diversos reforçadores generalizados importantes originam-se em ocasiões em que o comportamento é reforçado por outra pessoa. ... Outra pessoa provavelmente reforçará apenas aquela parte de nosso comportamento que aprova e qualquer sinal de sua aprovação torna-se assim por si próprio reforçador. (pp. 86-87)

Nesse sentido, é importante ressaltar a ação do grupo na seleção dos comportamentos, posto que muitas das consequências do comportamento são mediadas por outras pessoas. A possibilidade de selecionar o comportamento de outros indivíduos se dá, principalmente, mediante ao reforço social, o qual necessita da presença de outra pessoa ou grupos de pessoas. De forma generalizada, a atenção, aprovação, afeição ou mesmo o desprezo e a rejeição podem ser considerados como formas de reforço social utilizados pela comunidade verbal em que se está inserido e, portanto, selecionam comportamentos do indivíduo (Skinner, 1953/2003). Dessa forma, pode-se observar que a cultura também exerce importante papel seletivo.

Vale ressaltar que tanto o reforçamento positivo quanto o negativo são formas de controle comportamental, porém, apenas o reforço negativo está relacionado ao controle aversivo. Ambos envolvem o aumento da probabilidade de emissão do comportamento, mas são processos distintos; este se dá através da remoção de uma estimulação aversiva, enquanto aquele se dá pela apresentação de um estímulo reforçador.

A consequência imediata da agressão é a remoção da estimulação aversiva. Todavia, o comportamento pode produzir consequências em longo prazo, próprias de um processo que tenderia a diminuir a probabilidade do comportamento, consequências ditas punitivas. Processos penais, multas e prisões poderiam se originar da agressão, como forma de punição, porém, seu surgimento ocorreria apenas em tempo delon- 
gado. Porém, além do fato de o comportamento estar mais sensível às consequências imediatas (Albuquerque \& Paracampo, 2010; Catania, 1998/1999; Millenson, 1967/1975; Skinner, 1969, 1987), pode ocorrer de o agressor nunca entrar em contato com as consequências aversivas que seu comportamento possa produzir, primeiramente, pois não há, no atual código penal, agravantes para a homofobia, e pelo reduzido número de denúncias registradas, como indica o relatório da Secretária de Direitos Humanos da Presidência da República (Bernardes et al., 2012).

\section{Sobre a Perspectiva da Vítima}

Sobre a ótica da vítima de agressão, podem-se observar as consequências que o próprio indivíduo deve ter entrado em contato. Mas, para tal, faz-se necessário compreender melhor o conceito de "punição" para a análise do comportamento. De acordo com Sidman (1989/2003), a punição pode ser definida como "o término ou retirada de alguma coisa que comumente seria reforçador positivo" (p. 59) ou como "a produção de algo que normalmente seria um reforçador negativo. Eu defino estas duas contingências de punição. . . . Como reforçadores, punidores vêm depois do comportamento" (p. 59). Dessa forma, pode-se encarar "punidores" como consequências do comportamento, e, portanto, retroagem sobre o mesmo, tendo como efeito a diminuição da probabilidade de emissão do comportamento em contextos similares. Embora a punição seja amplamente conhecida pelo seu efeito na probabilidade de emissão do comportamento, defini-la a partir deste pode gerar problemas, posto que outros procedimentos, como a extinção operante, possuem efeitos análogos sobre a emissão do comportamento, sendo o processo distinto.

Retomando o exemplo anterior, vamos ponderar sobre o fato dos dois homens estarem abraçados. Independente da função que este comportamento tenha, é um comportamento operante e, portanto, também produz consequências. Possivelmente, estar abraçado produziria consequências como carinho, afeto, companheirismo ou amizade $^{4}$, um em relação ao outro, mas, infelizmente, houve a produção de uma estimulação aversiva, a agressão. Muito provavelmente, dependendo da intensidade da violência sofrida, os dois homens não voltem a se abraçar no mesmo local, ou em contextos parecidos, ou na presença de pessoas com alguma característica que lembre o agressor, ou, simplesmente, não abraçam mais.

Torna-se, então, questionável os motivos de se utilizar a punição como forma de controle do comportamento. De acordo com Millenson (1967/1975),

o procedimento de punição parece ser usado frequentemente não porque funcione tão bem, mas porque (1) tem efeito imediato; e (2) sua liberação e/ou efeitos colaterais são quase sempre positivamente reforçadores para a pessoa que administra a punição . . . No momento, todavia, o comportamento indesejável é temporariamente suprimido e essa supressão serve para proporcionar reforçamento positivo imediato para o comportamento do punidor. (p. 399)

Ou seja, ao utilizar-se de punição, o comportamento que está sendo punido cessa imediatamente, sendo reforçador a quem está punindo. Outro fator que influencia no uso de punição como técnica de controle comportamental é a facilidade no arranjo das contingências. Ou seja, "a curto prazo, a punição é frequentemente o caminho fácil . . . é fácil no sentido de que não requer treinamento especial" (Sidman, 1989/2003, pp. 232-233). Porém, inicialmente o comportamento punido seja suprimido, gradualmente ele volta a ocorrer (Sidman, 1989/2003). Embora a consequência seja imediata e o comportamento punido para de acontecer, não há garantias de que o mesmo não volte ocorrer. Dessa forma, pode ser que os dois homens do exemplo possam voltar a se abraçar, pois os efeitos de uma punição são perdidos ao longo da passagem do tempo.

4 Embora estas sejam classes amplas de comportamento, envolvendo diferentes topografias, seu valor reforçador deve-se, muito provavelmente, a história de reforçamento e ao reforço social. 
Não obstante, além de não impedir que o comportamento pudesse ser reestabelecido, punições geram efeitos colaterais tão nocivos quanto os próprios métodos de punir. Segundo Sidman (1989/2003),

Efeito colateral é um termo que frequentemente se refere a consequências não-pretendidas e supostamente pouco importantes ou improváveis de drogas, mas, como todos sabemos, os efeitos colaterais de uma droga frequentemente são suas características mais importante. ... Os efeitos colaterais da punição também, longe de serem secundários, frequentemente tem significado comportamental consideravelmente maior que os esperados "efeitos principais". (p. 94)

O primeiro efeito diz respeito ao condicionamento da punição, que se caracteriza por "dar a qualquer sinal de punição a habilidade de punir por si mesmo" (Sidman, 1989/2003, p. 101). Este processo é um exemplo de controle ambiental, no qual, algum estímulo presente no ambiente sinaliza que, naquele contexto, há maior probabilidade de ocorrer uma punição. Sobre tal, a análise experimental do comportamento fornece vários dados de experimentos realizados, como por exemplo , em uma situação na qual o sujeito experimental (usualmente um infra-humano) leva um choque após um sinal luminoso estar presente por um tempo. Com a repetição do experimento, o sinal luminoso passa a ter características de estímulo aversivo, exercendo os mesmos efeitos que o choque exerceria.

O mesmo pode ser transposto para humanos, em situações não laboratoriais, ou seja, no cotidiano. A vítima de uma violência pode não mais ir ao local onde a agressão ocorreu, ou pode ser punido, cessando o comportamento que estaria emitindo na presença do agressor ou de pessoas com características semelhantes e, em alguns casos, o indivíduo pode não mais sair de casa, isolando-se socialmente, parando, inclusive, de trabalhar.

De acordo com alguns teóricos, a supressão momentânea do comportamento ocorre à transferência da aversividade a um estímulo neutro diz respeito a respostas emocionais, outro efeito colateral da punição.
Quando uma resposta operante é punida, o primeiro efeito observado é uma redução imediata na sua freqüência. Para Skinner, essa redução se deve à eliciação de respostas emocionais (processo respondente), as quais são incompatíveis com a emissão da resposta (operante) punida. Em seguida, essas respostas emocionais são eliciadas tanto pelo contato com estímulos ambientais presentes na sua ocorrência anterior, como pelas primeiras instâncias de ocorrência da resposta (operante) que foi originalmente seguida de estimulação aversiva. Estes dois eventos, por terem sido emparelhados com a estimulação aversiva, tornam-se estímulos aversivos condicionados e, consequentemente, passam a prevenir a ocorrência da resposta operante, originalmente punida (Mayer \& Gongora, 2011).

Respostas emocionais podem ser entendidas "como fenômenos complexos que envolvem tanto a eliciação de condições corporais específicas quanto à emissão de operantes" (Darwich $\&$ Tourinho, 2005, p. 112). Ou seja, em situações de punição, a nível fisiológico há liberação de várias substâncias químicas, enquanto que a nível publicamente observável há emissão de respostas como xingar, bater e correr. Nesse sentindo, uma resposta emocional, como a raiva, encontram-se presentes componentes fisiológicos e comportamentais. Não se está afirmando que as duas respostas, a emocional e a pública, estão em relação de causa-efeito, mas sim, que ambas ocorrem simultaneamente.

Não obstante, o indivíduo pode começar a emitir comportamentos incompatíveis com o comportamento punido. De acordo com Meyer, Oshiro, Donadone, Mayer e Starling, (2008), a punição fortalece formas incompatíveis de comportamento, pois reduziria a estimulação aversiva condicionada, sendo reforçado por isso. Em um exemplo citado por Meyer et al. (2008), tapar a boca previne uma resposta falada e, embora o exemplo não esteja descrito, assume-se que "tapar a boca" poderia ser uma resposta incompatível com um contexto de discussão. No que tange a homossexualidade, permanecer em casa, evitar relacionamentos ou até o ficar "no armário", expressão utilizada para designar pessoas que não assumem sua homossexualidade, podem 
ser consideradas como respostas incompatíveis e que preveniriam uma estimulação agressiva, uma agressão.

Mais além, não apenas respostas incompatíveis podem ser reforçadas, mas também, respostas opostas a situação. $\mathrm{O}$ que se chama de "formação reativa" em algumas escolas tradicionais da psicologia é, de acordo com Sidman (1989/2003), interpretado pela análise do comportamento como a emissão de comportamentos contrários ao comportamento que foi seguido pela produção de uma estimulação aversiva. Investir em relacionamentos heterossexuais - ainda que esta não seja a orientação sexual da pessoa - ou entrar para ordens religiosas e fazer o voto celibatário podem ser considerados como comportamentos que foram fortalecidos devido a uma punição (a qual pode estar presente ao longo na história de aprendizagem do organismo). $\mathrm{Ou}$ ainda, pode ser que a agressão por parte de alguns homofóbicos seja decorrente da sua própria homossexualidade, punida ao longo de sua história.

\section{Conclusões}

Por trás de episódios de violência contra homossexuais, encontra-se um contexto, responsável pela emissão das respostas agressivas. A homofobia, assim popularmente denominada, pode não ocorrer em todos os locais ou com todas as pessoas identificadas com o universo LGBT, mas nem por isso, sua ocorrência ou relevância deve permanecer oculta aos olhos da ciência ou da elaboração de políticas públicas - ela ocorre, e isto é um fato.

Mais além, não se pode considerar qualquer ato como sendo uma violência homofóbica. Deve-se olhar aos comportamentos a partir de sua função em determinados contextos. Chamar alguém de "viadinho" pode ser sim uma forma de agressão, se com tal palavra cause na vitima sentimentos de humilhação, constrangimento, menosprezo ou desvalia alguém. Todavia, em uma relação onde ambos utilizam tal termo como sendo uma forma amistosa de comunicação, sem que um se sinta inferior ao outro, não se pode falar em homofobia. Atentar-se ao contexto pode auxiliar, em muito, a não cometer erros em acusar uma pessoa de ser homofóbica.

Cabe, então, pensar sobre os motivos plausíveis de considera-se a homofobia como uma forma de agressão que mereça atenção especial. Embora se tenha discorrido sobre o controle aversivo relacionado com episódios de violência contra homossexuais, é valido apontar que os efeitos da punição se dão sobre o comportamento consequenciado por uma estimulação aversiva, mas, o agressor não estaria agindo na perspectiva do recorte temporal aqui adotado. Sua agressão não seria por ver dois homens abraçados, comportamento que pode ser comum em uma relação pai-filho, seu ataque seria direcionado à homossexualidade. Dentro da ciência, sobre tudo as ciências biológicas, observa-se uma tendência a considerar a homossexualidade como algo natural, biológico, ocorrendo em diferentes espécies (Bagemihl, 1999; Harrold, 1999; Menezes, 2005; Sommer \& Vasey, 2006; Vasey, 1995).

Embora se discuta sobre tal, fato é que não se explicou a origem da homossexualidade. Partindo-se de um ponto de vista pragmático, não se faz necessário explicar as possíveis causas do fenômeno da homossexualidade para que se promovam políticas públicas que incidam sobre o combate e a prevenção dessa forma de violência, uma vez que a homossexualidade está em vias de ser naturalizada, tal qual a cor da pele ou o gênero. Talvez, tal qual ocorre com essas duas populações, possa haver uma contenção nos números de violência a partir de formulações de leis que criminalizem a homofobia.

Tal ação poderia ter efeitos imediatos, mas, ainda assim se faria necessário adoção de medidas que combatessem o preconceito a médio e longo prazo. Os investimentos em educação, sobre tudo na educação sexual emancipatória - que propõe a vivência plena da sexualidade, contextualizada sócio-historicamente, a prática da autonomia e o questionamento dos valores e preconceitos postos (Figueiró, 2010; Nunes \& Silva, 2000; Poletti, 2010) - pode se configurar como uma medida que vise o combate a homofobia e o respeito à diversidade sexual. 
Obviamente, a temática é polêmica e envolve diferentes instâncias e instituições sociais, tangendo valores e dogmas sócio-históricamente, postos e reproduzidos, tal qual sua caracterização pela adoção de ações, por vezes coercitivas, incididas sobre uma população que, em momento algum, teve possibilidade de escolha sobre sua própria orientação sexual. Todavia, deixar o fenômeno da homofobia ao relento, sem preocupar-se cientificamente com o mesmo, é reafirmar o preconceito em suas diferentes formas e incidências. No presente artigo, optou-se por fazer uma análise preliminar que envolvesse alguns dos possíveis processos comportamentais envolvidos na homofobia.

Ainda se fazem necessários mais estudos teóricos, principalmente sobre a prevalência da agressão junto à população LGBT. Possivelmente, a violência homofóbica ocorra mais frequente do que suas relativas denúncias ou sua visibilidade. Assim, entender as causas de tal fenômeno, sua incidência na população, e as formas como se manifesta faz-se importante para compreender e combater agressões, dando maior equidade de direitos entre a população. Além disso, a partir do conhecimento do fenômeno, é possível pensar em diversas estratégias que poderiam aumentar o número de denúncias, se aproximando do número real de casos existentes, o que daria maior visibilidade ao problema, refletindo em políticas públicas de combate a essa violência.

\section{Referências}

Adams, H. E., Wright, L. W., \& Lohr, B. A. (1996, August). Is homophobia associated with homosexual arousal? Journal of Abnormal Psychology, 105(3), 440-445

Albuquerque, L. C., \& Paracampo, C. C. P. (2010, abr.). Análise do controle por regras. Psicologia: USP, 21(2). Recuperado em http://www. revistasusp.sibi.usp.br/pdf/psicousp/v21n2/ v21n2a04.pdf

Bagemihl, B. (1999). Biological exuberance: Animal homosexuality and natural diversity. New York: St. Martin's Press.
Baum, W. M. (2008). Compreender o behaviorismo: Comportamento, cultura e evolução (2. ed.). São Paulo, SP: Artmed. (Original publicado em 2005)

Bernardes, G., Calaf, P. P., Lindgren, Y., Abramovay, M., Carrara, S., Mott, L., ...Gosse, C. (2012). Relatório sobre a violência homofóbica no Brasil: $O$ ano de 2011. Brasília, DF: Secretaria de Direitos Humanos da Presidência da Republica. Recuperado em http://www.abglt.org.br/docs/ Relatorio-LGBT_SDH.pdf

Cassado, D. da C., Gallo, A. E., \& Williams, L. C. de A. (2003). Post-traumatic stress disorder in women victims of domestic violence: A pilot study. Perfil \& Vertentes, 15(1), 99-108.

Catania, A. C. (1999). Aprendizagem: Comportamento, linguagem e cognição (4. ed., D. G. Souza, Coord. Trad.). Porto Alegre, RS: Artes Médicas Sul. (Original publicado em 1998)

Darwich, R. A., \& Tourinho, E. Z. (2005, jun). Respostas emocionais à luz do modo causal de seleção por conseqüências. Revista Brasileira de Terapia Comportamental e Cogniti$v a, 7(1)$. Recuperado em http://pepsic.bvsalud. org/scielo.php?script=sci_arttext\&pid=S1517$-55452005000100011 \& \operatorname{lng}=$ pt\&nrm=iso

Day, V. P., Telles, L. E. de B., Zoratto, P. H., Azambuja, M. R. F., Machado, D. A., Silveira, M. B., ...Blank, P. (2003). Violência doméstica e suas diferentes manifestações. Revista de Psiquiatria do Rio Grande do Sul, 25(Suppl. 1), 9-21. doi:10.1590/S0101-81082003000400003

Drydakis, N. (2009, August). Sexual orientation discrimination in the labour market. Labour Economics, 16, 364-372. doi:10.1016/j.labeco.2008.12.003

Figueiró, M. N. D. (2010). Educação sexual: Retomando uma proposta, um desafio (3. ed.). Londrina, PR: Editora da Universidade Estadual de Londrina.

G1 Bahia. (2012). Irmãos são agredidos ao andarem abraçados em Camaçari; um morreu. Portal G1. Recuperado em http://g1.globo.com/bahia/noticia/2012/06/irmaos-sao-agredidos-ao-andarem-abracados-em-camacari-um-morreu.html

Harrold, M. (1999). Biological exuberance: Animal homosexuality and natural diversity. In HighBeam Encyclopedia. Chicago, IL: HighBeam Research. 
Haydu, V. B. (2009). Compreendendo os processos de interação do homem com seu meio ambiente. In S. R. Souza \& V. B. Haydu (Eds.), Psicologia comportamental aplicada: Avaliação e intervenção nas áreas do esporte, clínica, saúde e educação (pp. 9-35). Londrina, PR: Editora da Universidade Estadual de Londrina.

Kairys, S. W., Johnson, C. F., \& Committee on Child Abuse and Neglect. (2002). Technical report: The psychological maltreatment of children. Pediatrics, 109(4), e68. doi:10.1542/ peds.109.4.e68

Matos, M. A. (1999). Com o que o behaviorismo radical trabalha? In R. A. Banaco (Ed.), Sobre comportamento e cognição (pp. 45-53). Santo André, SP: Arbytes.

Mayer, P. C. M., \& Gongora, M. A. N. (2011). Duas formulações comportamentais de punição: Definição, explicação e algumas implicações. Acta Comportamentalia, 19(4). Recuperado em http://www.revistas.unam.mx/index.php/acom/ article/view/36938

Menezes, A. B. de C. (2005). Análise da investigação dos determinantes do comportamento homossexual humano. Belém, PA: Centro de Filosofia e Ciências Humanas, Universidade Federal do Pará.

Meyer, S. B., Oshiro, C., Donadone, J. C., Mayer, R. C. F., \& Starling, R. (2008, jun.). Subsídios da obra "Comportamento Verbal" de B. F. Skinner para a terapia analítico-comportamental. Revista Brasileira de Terapia Comportamental e Cognitiva, 10(1), 105-118 Recuperado em http://pepsic.bvsalud.org/ scielo.php?script $=$ sci_arttext\&pid $=\mathrm{S} 1517$ $-55452008000100009 \& \operatorname{lng}=\mathrm{pt}$

Millenson, J. R. (1975). Princípios de análise do comportamento. Brasília, DF: Coordenada. (Original publicado em 1967)

Nardi, P. M., \& Bolton, R. (1991) "Gay-bashing”: Violence and aggression against gay men and lesbians. Advances in Psychology, 76, 349-400. doi:10.1016/S0166-4115(08)61062-6

Nunes, C., \& Silva, E. (2000). A educação sexual da criança: Subsídios teóricos e propostas práticas para uma abordagem da sexualidade para além da transversalidade. São Paulo, SP: Autores Associados.
O’Brien, J. (2001). Heterosexism and homophobia. In N. J. Smelser \& P. B. Baltes (Eds.), International Encyclopedia of the Social \& Behavioral Sciences (pp. 6672-6676). London: Elsevier.

Parrott, D. J. (2008, July). “A theoretical framework for antigay aggression": Review of established and hypothesized effects within the context of the general aggression model. Clinical Psychology Review, 28(6), 933-951. doi:10.1016/j. cpr.2008.02.001

Parrott, D., \& Zeichner, A. (2005, January). Effects of sexual prejudice and anger on physical aggression toward gay and heterosexual men. Psychology of Men \& Masculinity, 6(1), 3-17.

Poletti, E. S. (2010). Dos jovens de Gaia e Urano aos adolescentes do Google em seus processos de educação sexual (Dissertação de mestrado em Educação, Universidade do Estado de Santa Catarina, Florianópolis, SC, Brasil).

Sidman, M. (2003). Coerção e suas implicações. Campinas, SP: Livro Pleno. (Original publicado em 1989)

Skinner, B. F. (1969). Contingencies of reinforcement: A theorical analyses. New York: Appleton-Century-Crofts.

Skinner, B. F. (1987). What is wrong with daily life in the western world. In B. F. Skiner (Ed.), Upon futher reflection (pp. 51-63). Englewood Cliffs, NJ: Prentice-Hall

Skinner, B. F. (2003). Ciência e comportamento humano (11. ed., J. C. Todorov \& R. Azzi, Trads.). São Paulo, SP: Martins Fontes. (Original publicado em 1953)

Sommer, V., \& Vasey, P. L. (2006). Homosexual behaviour in animals: An evolutionary perspective. Cambridge, UK: Cambridge University Press.

Vasey, P. L. (1995). Homosexual behaviour in primates: A review of evidence and theory. International Journal of Primatology, 16, 173-204. 